\title{
Hydrothermal Performance of Ethylene Glycol and Water Mixture in a Spiral Channel for Electric Motor Cooling
}

\author{
Ali Deriszadeh, Filippo de Monte, Marco Villani, and Lino Di Leonardo \\ Dipartimento di Ingegneria Industriale e dell'Informazione e di Economia (DIIIE), Universita \\ dell'Aquila. \\ Via Camponeschi, 19, 67100 L'Aquila AQ, Italy \\ E-Mail: ali.deriszadeh@graduate.univaq.it, Filippo.demonte@univaq.it, \\ marco.villani@univaq.it, lino.dileonardo@univaq.it.
}

\section{Keywords}

Cooling, electrical machine, electric vehicle, modelling, automotive application.

\begin{abstract}
This paper investigates the feasibility of a direct liquid cooling technique for the thermal management system of an electrical machine for automotive application. The cooling system is a closed liquid coolant loop employing a mixture of Ethylene Glycol and water as a coolant. General performance of the cooling system at different volume fractions of mixture of Ethylene Glycol and water is evaluated. Various geometry of the cooling system, and physical characteristics of the coolant fluid are studied. Thermal analyses of the cooling system are performed using computational fluid dynamics and 3D turbulent fluid motion analysis. According to analysis, influence of the critical parameters on the performance of the cooling system is studied.
\end{abstract}

\section{Introduction}

Recently, there is a great industry trend to develop hybrid and all electric vehicles by adding electric machines into powertrain of conventional vehicles. The hybrid powertrains are partly electrified while all electric powertrains are completely electrified by replacing conventional internal combustion engines with an electric machine. In both cases, designing an efficient electric machine is of significant importance. The efficient electric machine must have high power density and performance. This new application of electric machines demands new requirements that dedicated electric machines for vehicle application must meet them. One important requirement is ability to deliver high temporary peak torque with avoiding increasing size of electric machine [1]. On the other hand, size and cost play critical roles in developing application of electric machines in vehicle powertrain evolution. Using a proper cooling system, it is possible to enhance performance of electric machine without increasing its size [2]-[4]. This can improve the power density of the electric machine while the intended performance is satisfied. The importance of cooling systems grows significantly today since high power density is required for electric vehicles.

Moreover, high temperatures impact directly on the lifetime of an electric machine and increase the failure possibility of materials [5]-[6]. Therefore, thermal protection is vital for an electric machine. Increase of electric machine heating may damage winding insulations. This can lead to turn-to-turn or turn-to-ground short circuit faults [7]. This is more serious when electric machines operate in harsh environments like in-hub electric machines for electric vehicle application [8].

Regarding cooling methods, different systems were developed such as air cooling [9]-[11] and liquid cooling [12]-[14] systems. Air cooling systems offer a simple structure, but their cooling capacity is very limited. Therefore, thermal performance of air-cooling systems might not satisfy thermal system efficiency requirements of high torque/power density electric machines for electric vehicle applications. 


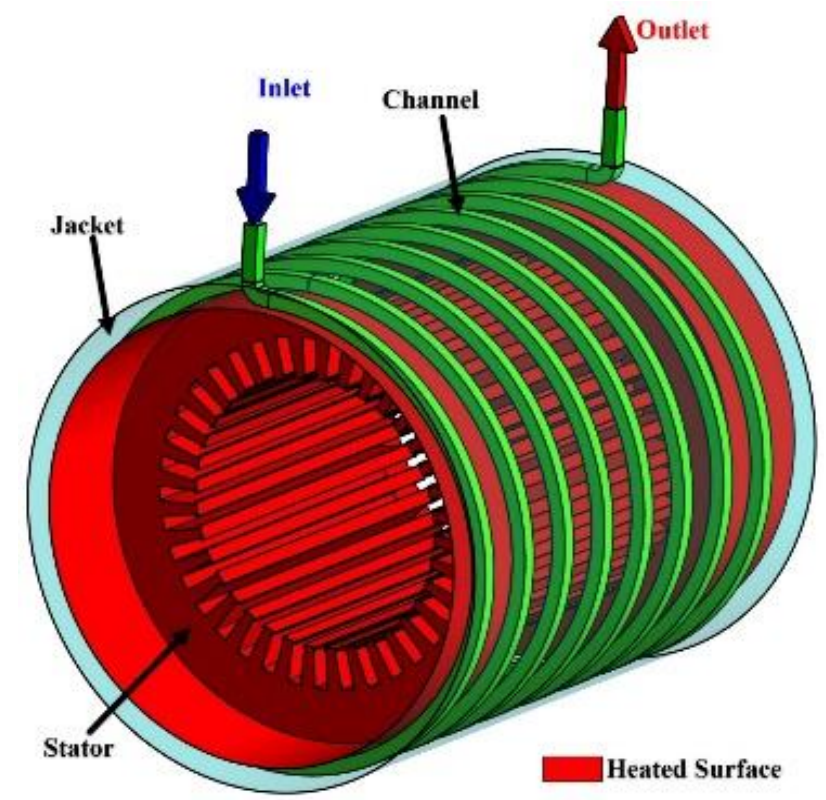

(a)
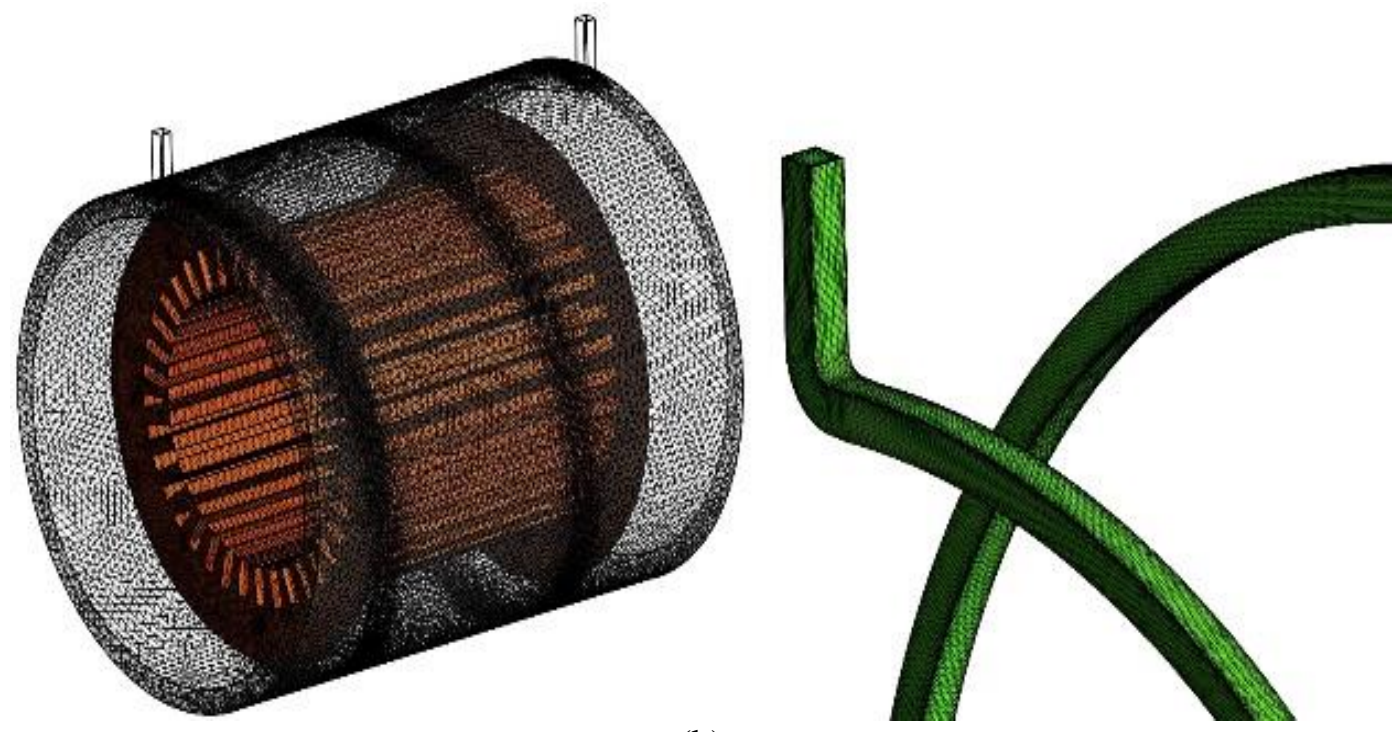

(b)

Fig. 1: Problem schematic representations, (a) Stator and cooling system, (b) non-uniform mesh grids.

Liquid cooling systems consist of fluid flow channels typically in the housing of the electric machine [15]-[16]. Liquid cooling systems present an enhanced heat transfer performance leading to higher allowance of current density and torque levels for a given size of an electric machine [17]. In [18] air cooling system of a permanent magnet retarder for heavy vehicle applications was replaced by a watercooling system and achieved improvements of heat conductivity using water cooling method were investigated. In [19], a water cooling was proposed for electric bus applications. Performance of the proposed cooling system was investigated under different standard driving cycles aiming at keeping temperature below $80^{\circ}$. According to experimental tests, it was reported that the water cooling effectively managed to retain windings temperature less than the maximum limit.

In this paper, a spiral channel liquid-cooling system is designed and investigated in terms of thermal impact of using different coolant fluids, different geometry of channels, and different physical characteristics of the coolant fluid. In the designed cooling system, both sides of end-winding areas are considered. Thermal analysis is implemented based on 3D turbulent fluid motion model. Computational fluid dynamics (CFD) analysis is used to compare simulation results and to explain impact of different parameters on performance of the cooling system. 


\section{Cooling system model}

The implemented cooling system consists of spiral channels created in the machine housing, surrounding the stator. Fig. 1.a shows the designed cooling system. The channel has a rectangular cross section with width of $6 \mathrm{~mm}$ and height of $6 \mathrm{~mm}$. Under-study coolants are water and different mixtures of water and Ethylene Glycol. Mixing ratios of Ethylene Glycol and water are 20:80, 40:60, and 60:40. Fig. 1.a shows three different geometrical components of the under-study cooling system and electric motor. It consists of the stator core, aluminum housing, and cooling channel inside the housing. Through the channel, a cooling liquid circulates refrigerating the motor.

In order to reduce computational expenses, simulation of some electrical parts such as windings have been avoided and from a separate thermal analysis, the generated heat flow has been determined. As can be seen in Fig. 1. a, only outer surfaces of the electric machine and the aluminum jacket have been considered. The inlet coolant temperature is given as $70^{\circ} \mathrm{C}$. To have some extra cooling margin for the designed cooling system, it has been assumed that whole the generated heat from the machine is taken away by the aluminum housing. A uniform heat flux of $3500 \mathrm{~W} / \mathrm{m} 2$ has been applied to outer surface of the stator. Turn number of the spiral channel are 2, 4, 6, and 8 turns. The coolant flow is turbulent and simulation studies are implemented under Reynolds numbers of 2500, 5000, 7500, and 10000. Boundary conditions are listed in Table I. Thermophysical properties of coolant fluids are summarized in Table II. In this paper, computational fluid dynamics (CFD) studies are performed using Ansys CFX. The pressure velocity coupling is achieved using Rhie-Chow interpolation technique. The convergence criterion for hydrodynamic and thermal parameters is considered to be 1e-6. k-W model is used for simulating turbulence inflow conditions.

In simulation of the system, non-uniform meshes are used so that adjacent to the channel walls due to the large gradients, smaller meshes are used. Mesh grids are shown in Fig.1. b.

\section{Governing equation of 3D turbulent fluid motion}

Some governing equations of heat transfer and fluid motion are conjugation equations, momentum and energy equations which are described in this section. The Reynolds number in the fluid flow analysis, is another characteristic of the flow which a non-dimensional quantity is representing the ratio of the inertial force to the viscous force. Reynolds number is used to determine whether the fluid flow is laminar or turbulent.

$$
R e=\frac{u_{a v e} D_{h}}{v}
$$

where $u_{\text {ave }}$ is the speed of the coolant fluid $(\mathrm{m} / \mathrm{s}), v$ is kinematic viscosity of the fluid (m2/s), and $D_{h}$ is channel diameter $(\mathrm{m})$. The channel diameter is one of the physical characteristics of the channel and is defined as follows.

$$
D_{h}=\frac{4 A_{c}}{p}
$$

where, $A_{c}$ is the cross-sectional area of the channel and $p$ is the duct area.

Another performance evaluating parameter of the channel is the friction coefficient that depends on geometry parameters of the channel and is calculated by the following equation.

$$
f=2 \Delta P \frac{D_{h}}{L} \frac{1}{\rho u_{i n}^{2}}
$$

The average Nusselt number is also a non-dimensional number indicating the heat transferred through the convection to the heat transmitted through the conduction and is obtained from the following equation.

$$
N u_{\text {ave }}=\frac{q^{\|} D_{h}}{k_{f}\left(T_{w}-T_{m}\right)}
$$

where, $T_{w}$, is the temperature of the channel wall and $T_{m}$ is the average bulk fluid temperature. To determine the overall thermal and fluid performance, we define the parameter PEC (Performance Evaluation Criterion) as follows.

$$
P E C=\frac{\left(\frac{N u_{\text {ave }}}{N u_{\text {ave }, S}}\right)}{\left(\frac{f}{f_{S}}\right)^{(1 / 3)}}
$$



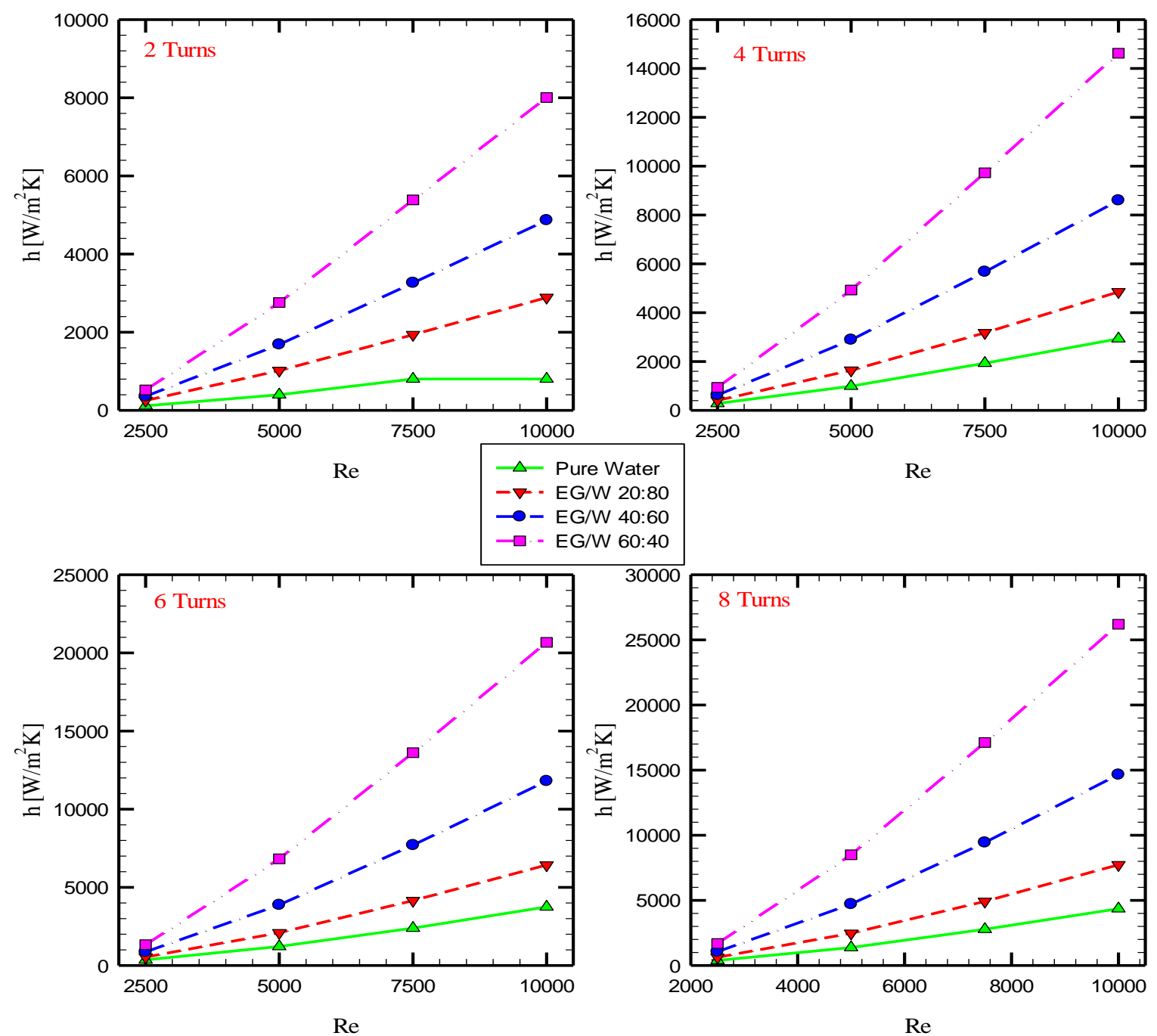

Fig. 2: Average convection heat transfer coefficient

where, $N u_{\text {ave, }}$ and $f_{s}$ are base parameters and are defined for the base fluid (pure water). Indeed, PEC indicates the ratio of the increase in heat transfer capability to the increase in the pressure drop caused by coolant fluid in comparison with the base fluid.

\section{Result and Discussion}

Average convection heat transfer coefficient and average Nusselt number for different Reynold numbers under different turn number of the spiral channel and at different volume fractions of Ethylene Glycol are shown in Fig 2 and Fig 3, respectively. As can be seen from Fig 2 and Fig 3, with increasing the Reynolds number, heat transfer coefficient and Nusselt number increase in all cases.

The main reason behind the increase of the heat transfer coefficient and Nusselt number is that by increasing the Reynolds number, fluid velocity increases and consequently fluid momentum increases resulting in increase of velocity and temperature gradients of the fluid in the near-wall regions. Accordingly, drag caused by the friction of the coolant fluid against the surface of the channel is enhanced and the coolant spends a shorter time contacting with the wall. As a result, heat transfer is significantly improved. 

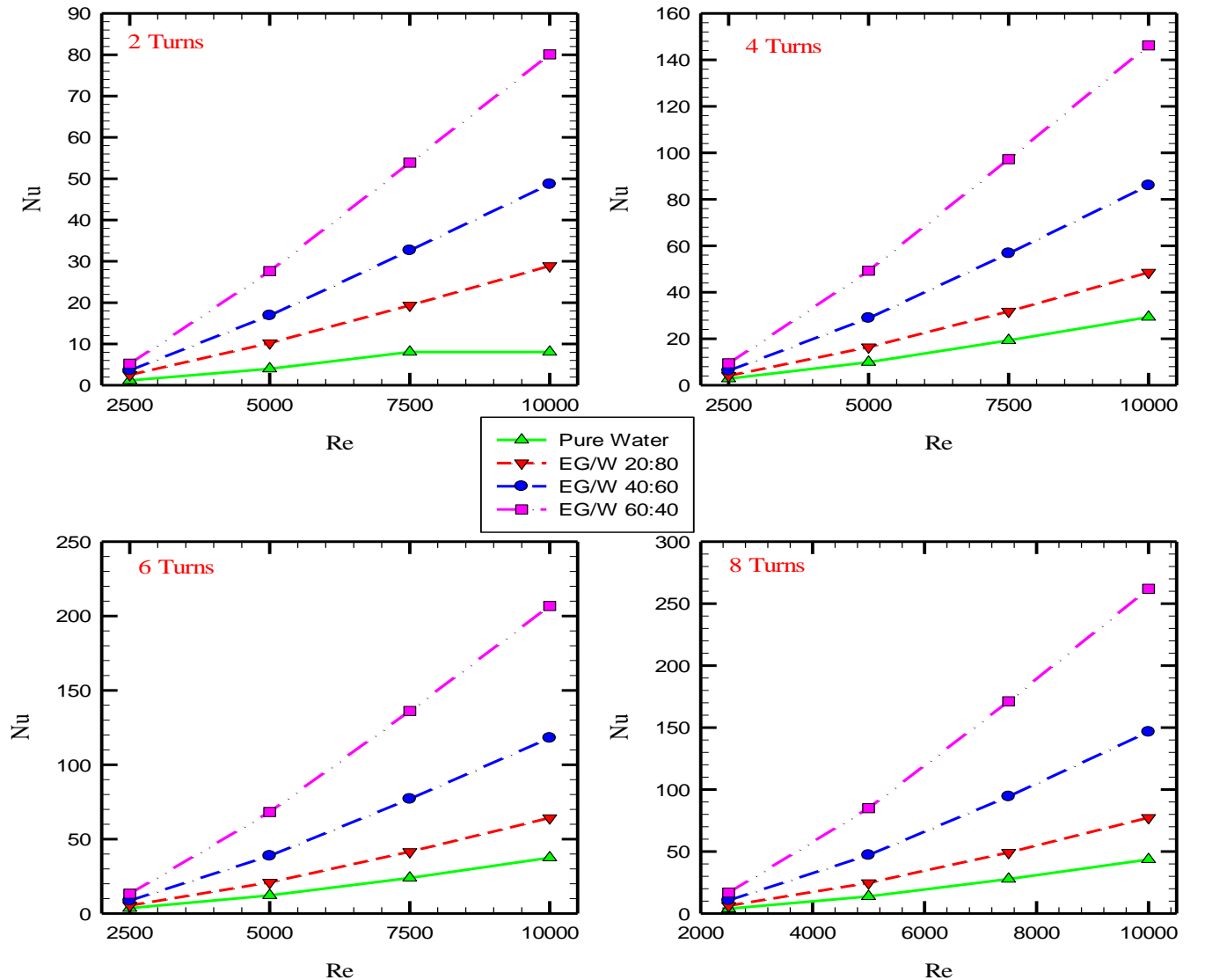

Fig. 3: Average Nusselt number
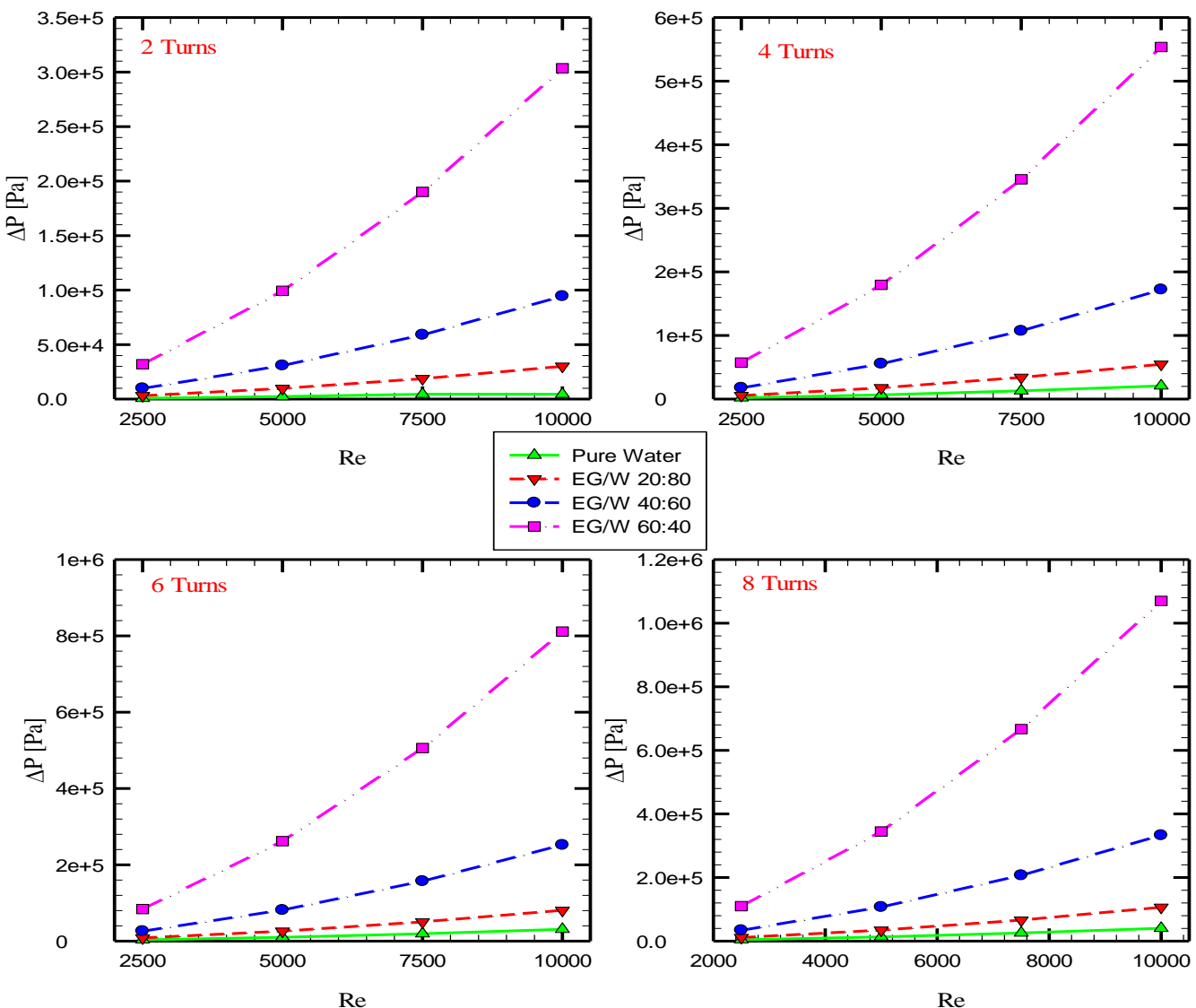

Fig. 4: Average pressure drop 

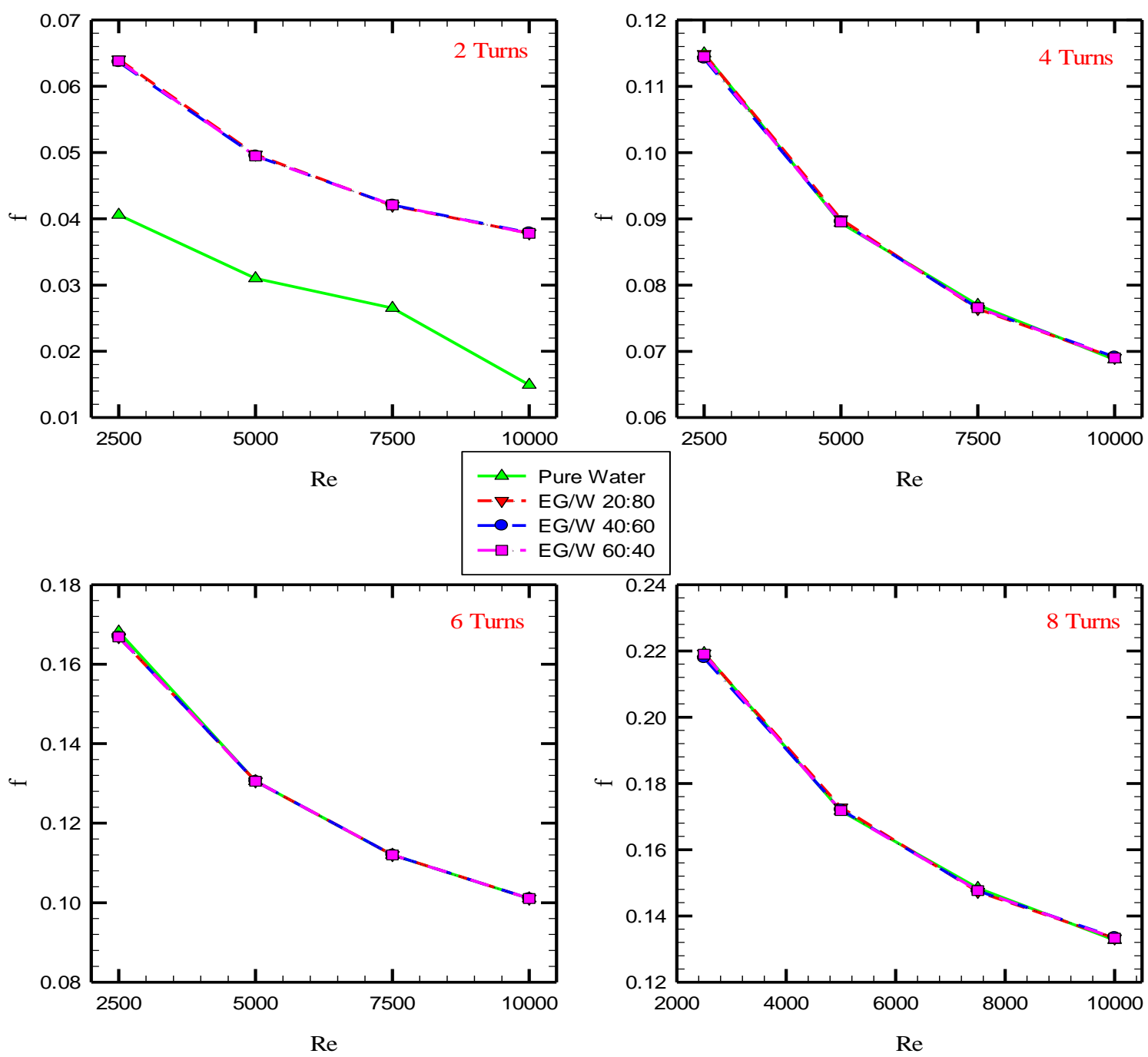

Fig. 5: Average fanning friction factor

Moreover, with increasing volume fraction of Ethylene Glycol, heat transfer coefficient and Nusselt number increase. With increasing volume fraction of Ethylene Glycol, ratio of the density to the viscosity decreases, therefore based on (1) velocity increases. This phenomenon is intensified in the cases where volume fraction of Ethylene Glycol is higher. In addition to the Reynolds number and volume fraction of Ethylene Glycol, with increasing turn number of spiral channels, heat transfer coefficient and Nusselt number increase. The reason is that increasing turn number of spiral channel results in increase of the length of the flow path of the fluid which leads to increase of contact level between fluid and the channel. In addition, higher number of turns leads to higher thermal coupling between channels because the channel's spin rate decreases, and the channels become closer to each other enhancing heat transfer with more uniform temperature distribution on the stator and the housing. Fig 4 and Fig 5 show average pressure drop and average fanning friction factor under different Reynolds numbers at different number of turns and volume fraction of Ethylene Glycol. From the figures, it can be concluded that with increasing the Reynolds number and number of turns, pressure drop increases. The reason is that the increase in number of turns leads to increase of length of the channel which leads to increase of slippery forces due to the increased fluidity of the coolant due to the increased volume fraction of ethylene glycol.

Fig 6 and Fig 7 show the performance evaluation criterion, PEC, diagrams relative to pure water and the turn number of 2 . It can be seen whether in the case where PEC is relative to pure water and relative to the turn number 2, the PEC values are greater than 1 . This means that by increasing the volume fraction of ethylene glycol and the number of turns, the thermal efficiency increases. In other words, the increase in the heat transfer coefficient is more significant than the increase in the pressure drop. 

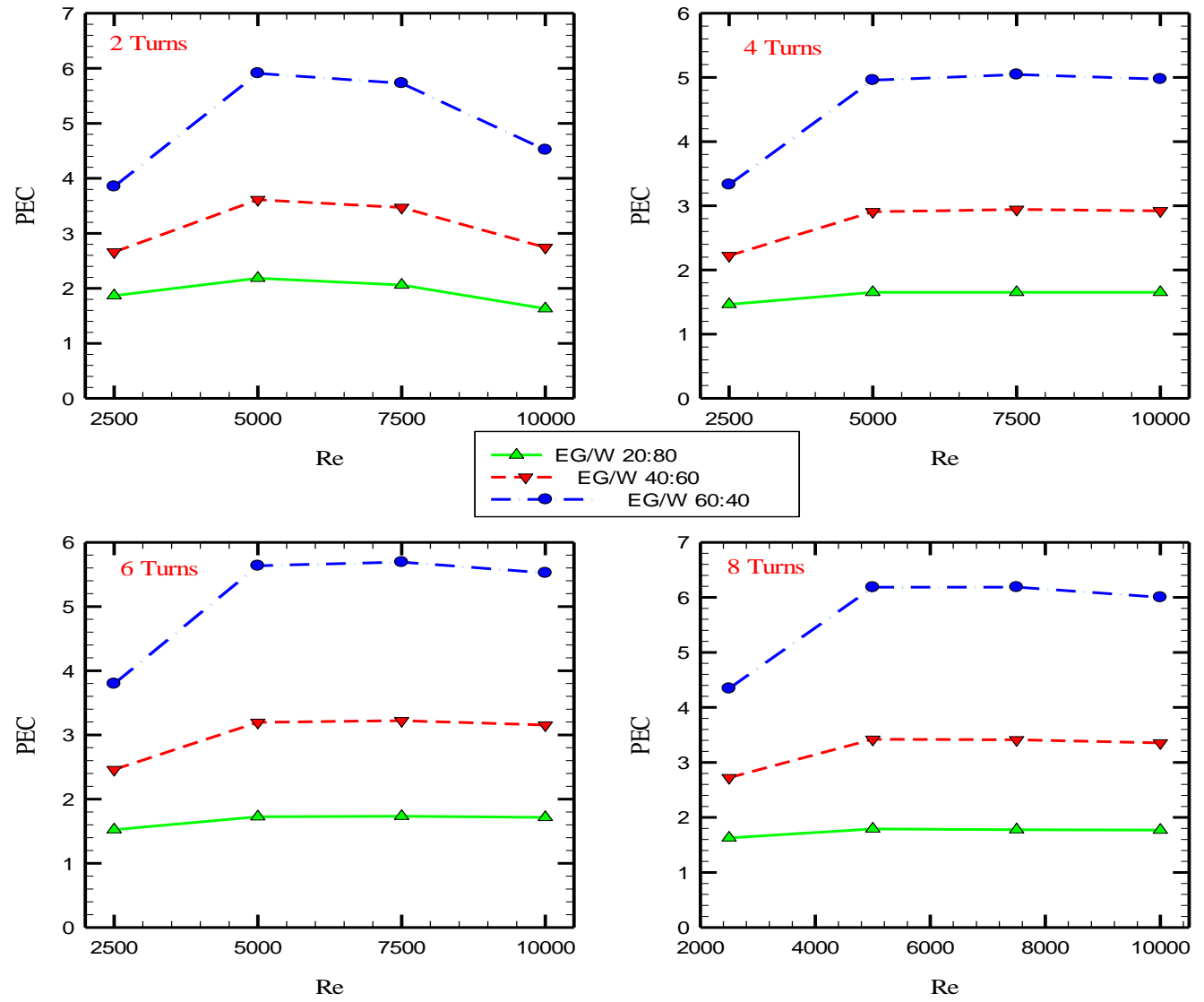

Fig 6. PEC Based on Pure Water
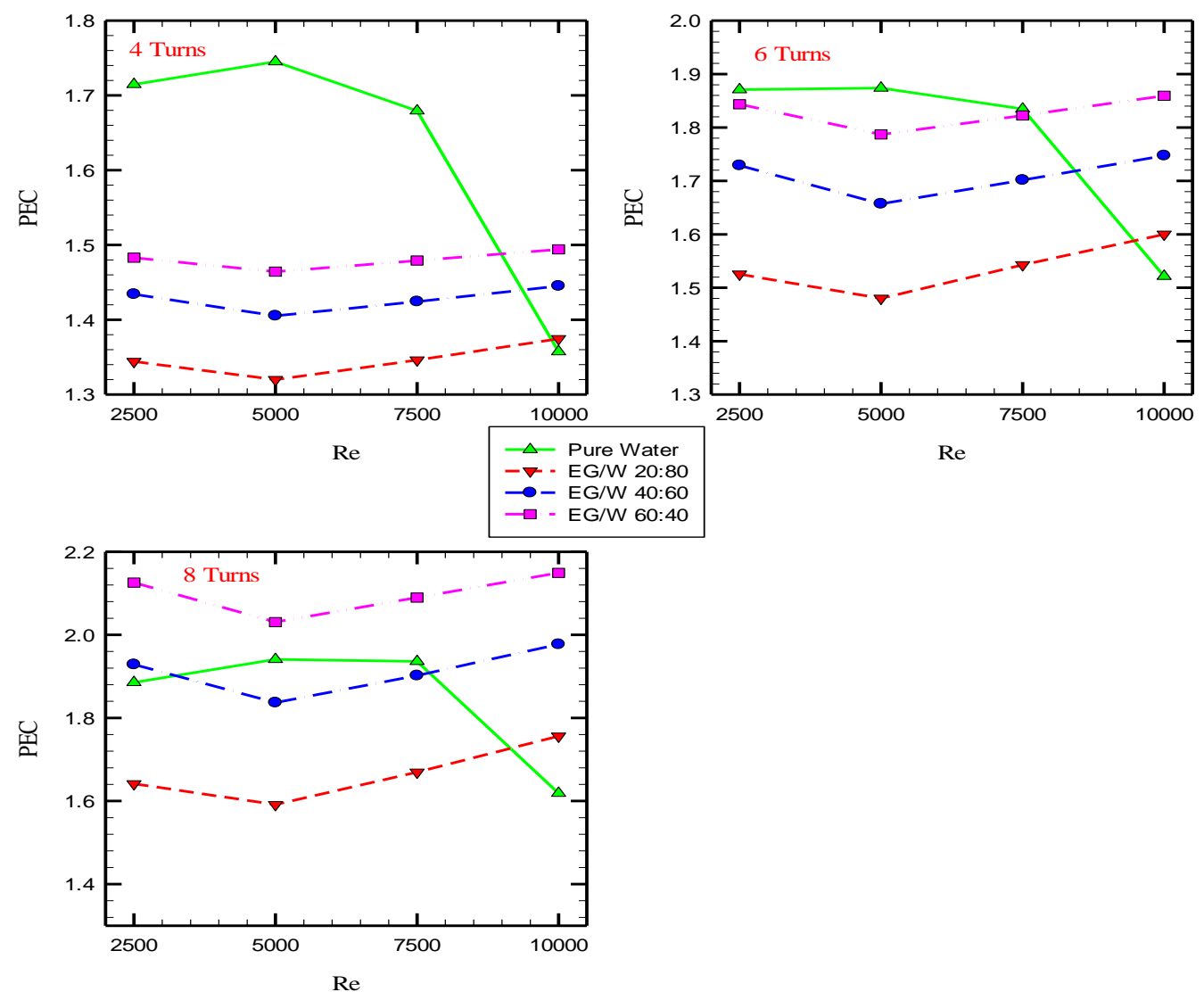

Fig. 7: PEC based on 2 Turns 


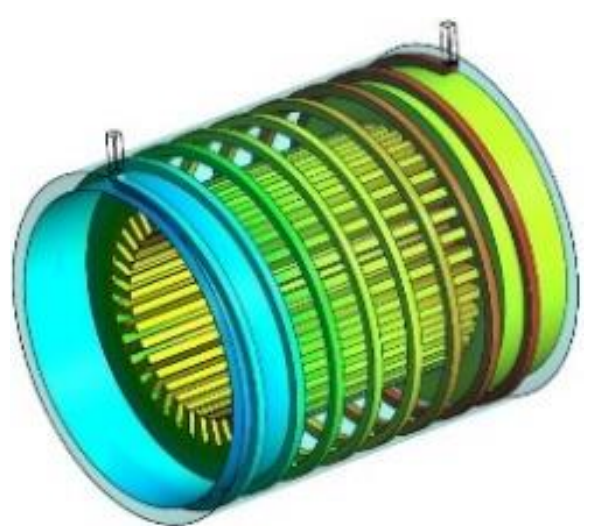

(a)

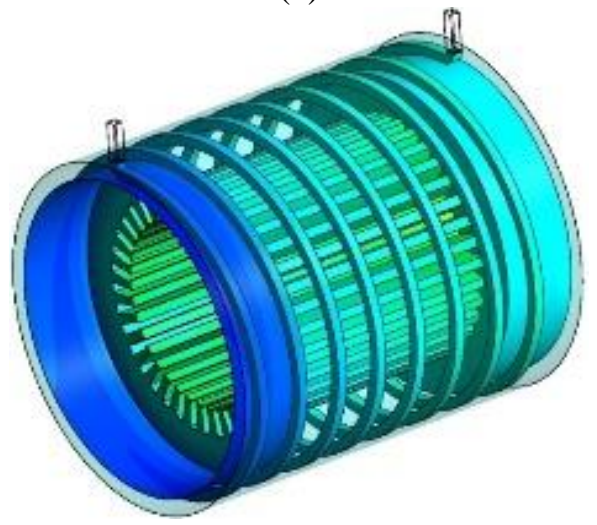

(c)

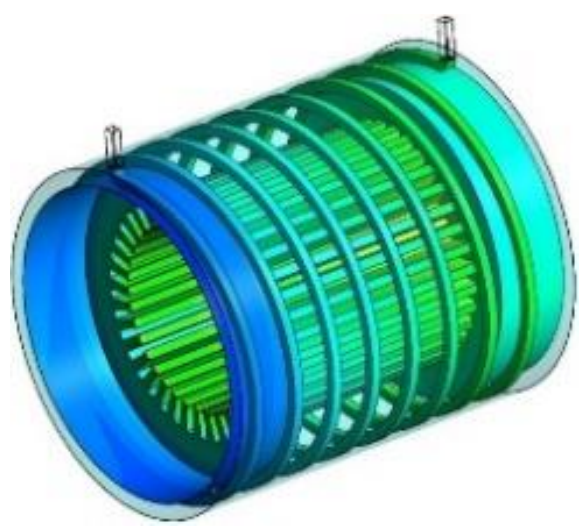

(b)

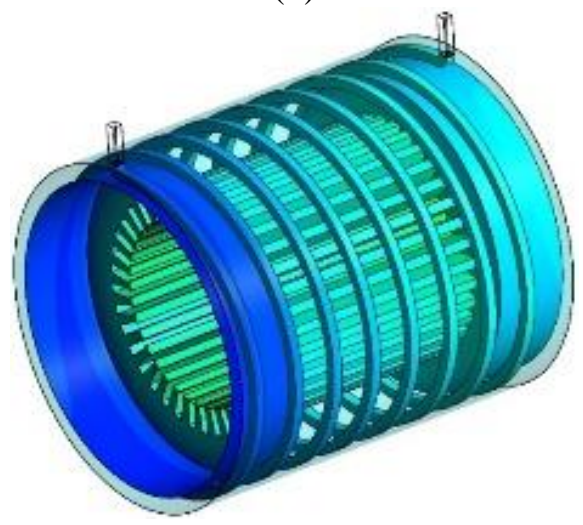

(d)

Temperature [K]

372.266
370.681
369.097
367.512
365.928
364.344
362.759
361.175
359.590
358.006
356.422
354.837
353.253
351.668
350.084
348.500
346.915
345.331
343.746

Fig. 8: Temperature distribution on heated surfaces and channel walls for (a) $\operatorname{Re}=2500$, (b) $\operatorname{Re}=5000$, (c) $\operatorname{Re}=7500$ and (d) $\operatorname{Re}=10000$

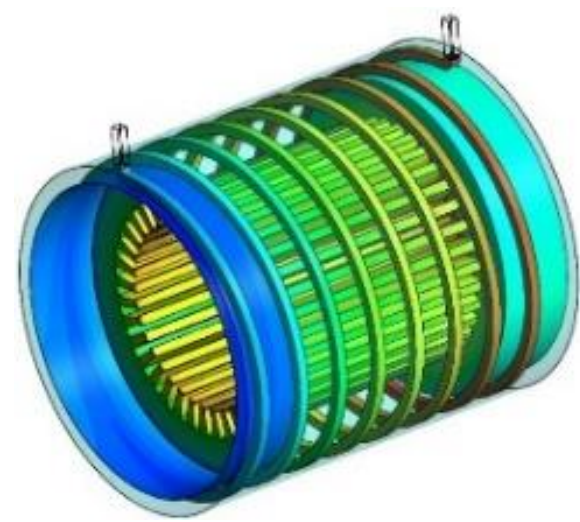

(a)

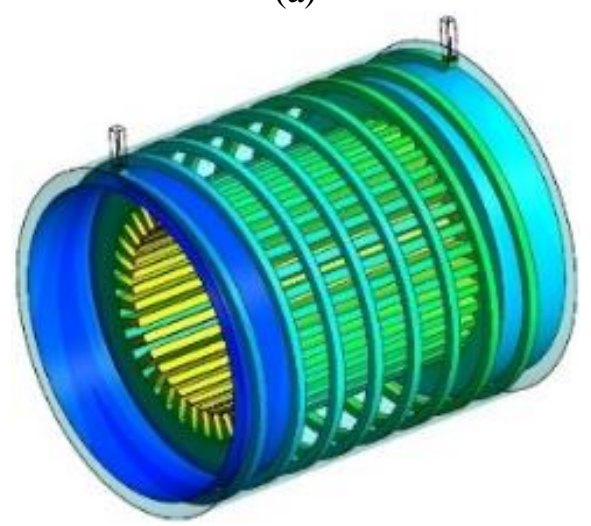

(c)

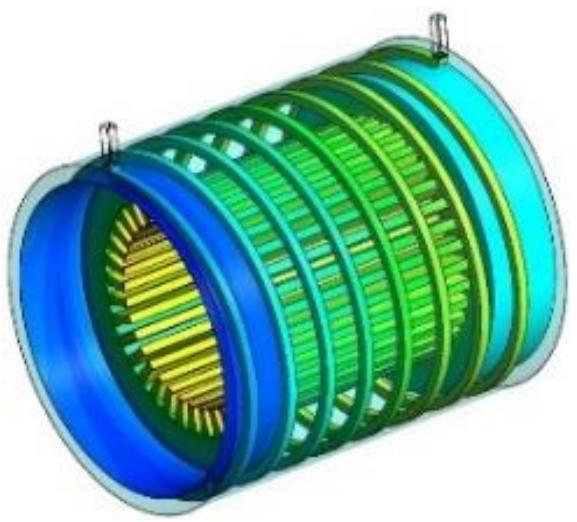

(b)

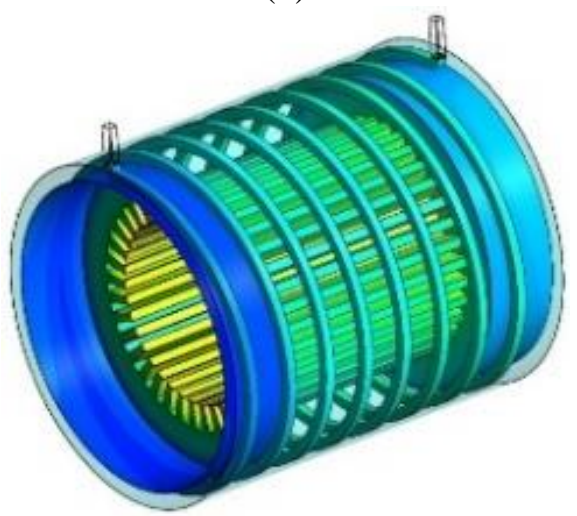

(d)

Fig. 9: Temperature distribution on heated surfaces and channel walls for (a) Pure Water, (b) EG/W 20:80, (c) EG/W 40:60 and (d) EG/W 60:40 


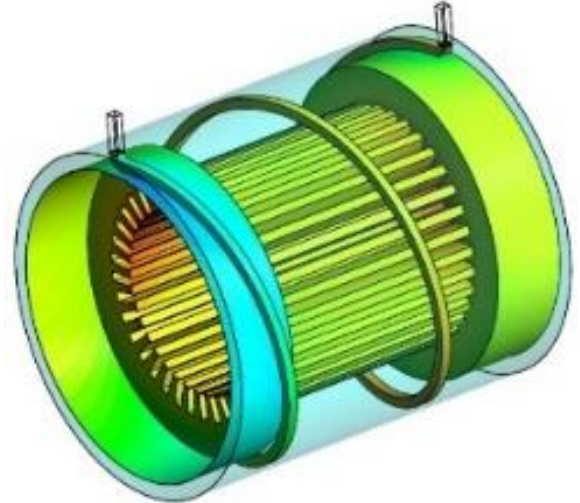

(a)

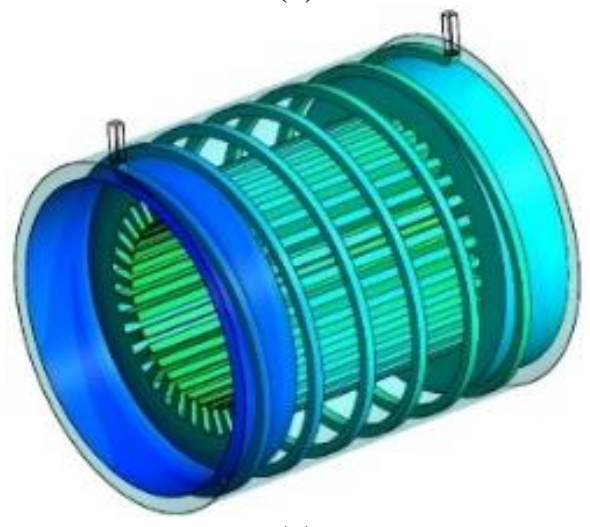

(c)

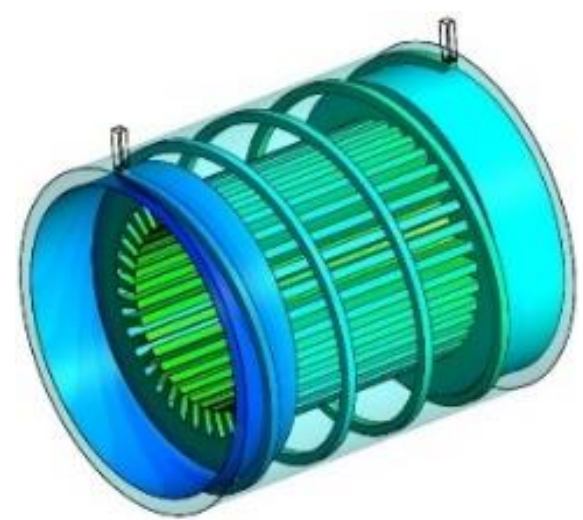

(b)

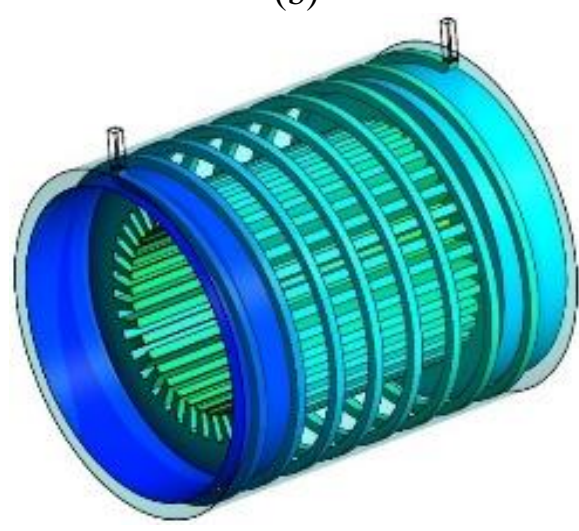

(d)

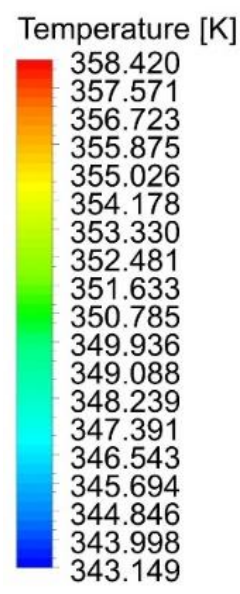

Fig. 10: Temperature distribution on heated surfaces and channel walls for (a) 2 Turns, (b) 4 Turns, (c) 6 Turns and (d) 8 Turns

Fig 8, Fig 9, and Fig 10 show temperature distribution on heated surfaces and channel walls for different Reynolds numbers, for different volume fractions of ethylene glycol, and different number of turns, respectively. Increasing all of the above-mentioned parameters will increase the heat transfer and result in a better cooling performance. This reduces the temperature of the external surface of the electric motor and also makes the temperature distribution more uniform on the outer surface of the electric motor.

\section{Conclusion}

In this paper, a 3D heat transfer and fluid flow analysis were performed for an electric machine cooling system with spiral channels employing mixture of ethylene glycol and water as coolant in the turbulent flow regime. Increasing turns of channels, the volume fraction of ethylene glycol, and the Reynolds number all increase the heat transfer coefficient. The defined performance evaluating parameter in this study, PEC, was used to evaluate the thermal and fluid flow performance of the cooling system. Higher values of this parameter indicate performance improvement of the designed cooling system. According to the simulation results, it was concluded that in comparison with pure water with turn number of 8 and at volume fraction of the Ethylene Glycol to water 60:40 in Reynolds number, $R e=5000$, the highest PEC was obtained. Also, regarding turn numbers, the turn number of 8 and volume fraction of ethylene glycol to water 60:40 in the Reynolds number of $\operatorname{Re}=10,000$ showed the highest PEC.

\section{References}

[1] M. Popescu, J. Goss, D. A. Staton, D. Hawkins, Y. C. Chong and A. Boglietti, "Electrical Vehicles-Practical Solutions for Power Traction Motor Systems," in IEEE Transactions on Industry Applications, vol. 54, no. 3, pp. 2751-2762, May-June 2018. 
[2] F. J. Márquez-Fernández, J. H. J. Potgieter, A. G. Fraser and M. D. McCulloch, "Experimental Validation of a Thermal Model for High-Speed Switched Reluctance Machines for Traction Applications," in IEEE Transactions on Industry Applications, vol. 54, no. 4, pp. 3235-3244, July-Aug. 2018.

[3] A. Di Gioia et al., "Design and Demonstration of a Wound Field Synchronous Machine for Electric Vehicle Traction With Brushless Capacitive Field Excitation," in IEEE Transactions on Industry Applications, vol. 54, no. 2, pp. 1390-1403, March-April 2018.

[4] G. Zhang, W. Hua, M. Cheng, B. Zhang and X. Guo, "Coupled Magnetic-Thermal Fields Analysis of Water Cooling Flux-Switching Permanent Magnet Motors by an Axially Segmented Model," in IEEE Transactions on Magnetics, vol. 53, no. 6, pp. 1-4, June 2017.

[5] D. L. Ransom and R. Hamilton, "Extending Motor Life With Updated Thermal Model Overload Protection," in IEEE Transactions on Industry Applications, vol. 49, no. 6, pp. 2471-2477, Nov.-Dec. 2013.

[6] F. Klocke, D. Lung, R. Schlosser, B. Döbbeler and S. Buchkremer, "Ecological lifecycle assessment of an electric drive for the automotive industry," 2012 2nd International Electric Drives Production Conference (EDPC), Nuremberg, 2012.

[7] R. Ginzarly, G. Hoblos and N. Moubayed, "Localizing Turn to Turn Short Circuit in HEV's Machine Using Thermal Finite Element Model," 2018 IEEE International Multidisciplinary Conference on Engineering Technology (IMCET), Beirut, 2018.

[8] C. J. Ifedi, B. C. Mecrow, S. T. M. Brockway, G. S. Boast, G. J. Atkinson and D. Kostic-Perovic, "FaultTolerant In-Wheel Motor Topologies for High-Performance Electric Vehicles," in IEEE Transactions on Industry Applications, vol. 49, no. 3, pp. 1249-1257, May-June 2013.

[9] L. Li, D. Pan and X. Huang, "Analysis and Optimization of Ironless Permanent-Magnet Linear Motor for Improving Thrust," in IEEE Transactions on Plasma Science, vol. 41, no. 5, pp. 1188-1192, May 2013.

[10] T. Nakahama, K. Suzuki, S. Hashidume, F. Ishibashi and M. Hirata, "Cooling airflow in unidirectional ventilated open-type motor for electric vehicles," in IEEE Transactions on Energy Conversion, vol. 21, no. 3, pp. 645-651, Sept. 2006.

[11] Y. Gai et al., "Cooling of Automotive Traction Motors: Schemes, Examples, and Computation Methods," in IEEE Transactions on Industrial Electronics, vol. 66, no. 3, pp. 1681-1692, March 2019.

[12] S. Nategh, A. Krings, O. Wallmark and M. Leksell, "Evaluation of Impregnation Materials for Thermal Management of Liquid-Cooled Electric Machines," in IEEE Transactions on Industrial Electronics, vol. 61, no. 11, pp. 5956-5965, Nov. 2014.

[13] M. Polikarpova et al., "Hybrid Cooling Method of Axial-Flux Permanent-Magnet Machines for Vehicle Applications," in IEEE Transactions on Industrial Electronics, vol. 62, no. 12, pp. 7382-7390, Dec. 2015.

[14] G. Zhu, X. Liu, L. Li, H. Chen, W. Tong and J. Zhu, "Cooling System Design of a High-Speed PMSM Based on a Coupled Fluidic-Thermal Model," in IEEE Transactions on Applied Superconductivity, vol. 29, no. 2, pp. 1-5, March 2019.

[15] A. Lajunen, Y. Yang and A. Emadi, "Recent Developments in Thermal Management of Electrified Powertrains," in IEEE Transactions on Vehicular Technology, vol. 67, no. 12, pp. 11486-11499, Dec. 2018.

[16] B. Zhang, R. Qu, J. Wang, W. Xu, X. Fan and Y. Chen, "Thermal Model of Totally Enclosed Water-Cooled Permanent-Magnet Synchronous Machines for Electric Vehicle Application," in IEEE Transactions on Industry Applications, vol. 51, no. 4, pp. 3020-3029, July-Aug. 2015.

[17] F. R. Ismagilov, N. Uzhegov, V. E. Vavilov, V. I. Bekuzin and V. V. Ayguzina, "Multidisciplinary Design of Ultra-High-Speed Electrical Machines," in IEEE Transactions on Energy Conversion, vol. 33, no. 3, pp. 1203-1212, Sept. 2018.

[18] L. Ye, D. Li, Y. Ma and B. Jiao, "Design and Performance of a Water-cooled Permanent Magnet Retarder for Heavy Vehicles," in IEEE Transactions on Energy Conversion, vol. 26, no. 3, pp. 953-958, Sept. 2011.

[19] P. Lindh et al., "Direct Liquid Cooling Method Verified With an Axial-Flux Permanent-Magnet Traction Machine Prototype," in IEEE Transactions on Industrial Electronics, vol. 64, no. 8, pp. 6086-6095, Aug. 2017. 